\title{
Pronase hydrolysis as a pretreatment for quantifying Maillard intermediates during toasting of cornflakes
}

\author{
Mario A. Cueto ${ }^{\text {a* }}$, Abel E. Farroni ${ }^{\mathrm{b}}$, And M. Del Pilar Buera ${ }^{\mathrm{a}}$

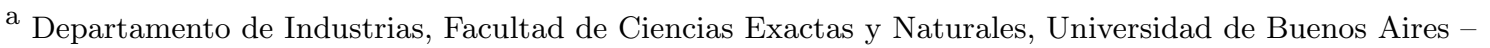 \\ CONICET. Intendente Güiraldes 2160 - Ciudad Universitaria - C1428EGA \\ b Laboratorio de Calidad de Alimentos Suelos y Aguas- EEA Pergamino, INTA. Av. Frondizi (Ruta 32) Km \\ 4,5 (2700), Pergamino, Provincia de Buenos Aires, Argentina \\ * Corresponding author \\ mariocueto@gmail.com \\ TEL: +5401161796109
}

Received: 12 June 2015; Published online: 18 April 2016

\begin{abstract}
Some of the products generated by the Maillard reaction are desired and very important for defining consumer acceptance of breakfast cereals. However, in recent years there has been an increased concern about compounds that are potentially harmful such as furfurals. The aim of this work was to analyze the effectiveness of protein hydrolysis with pronase as a pretreament for the evaluation of furfurals generated by the Maillard reaction during toasting of cornflakes and the parallel development of brown and fluorescent compounds. Furfurals were more accurately quantified with the pronase hydrolysis pretreatment because the protein matrix binds furfurals and fluorescent compounds. For control of the early reaction steps in the toasting process, the most sensitive parameter was fluorescence.
\end{abstract}

Keywords: Maillard; Furfural; HPLC; Hydroxymethylfurfural; Pronase; Fluorescence

\section{Introduction}

Heat processed foods undergo important physicochemical changes that lead to the final characteristics of the products. Among chemical changes, the Maillard reaction promotes the most important modifications in toasted foods. Some of them are desirable such as brown color and specific flavor or antioxidant compounds but others are detrimental such as the degradation of amino acids and an overall decrease in the nutritional value. Moreover, dietary intake of Maillard reaction products was the subject of an increasing number of investigations due to their implication in human health (Tessier \& BirlouezAragon, 2012).

Breakfast cereals such as cornflakes are increasingly consumed by adults and children and their production involves extensive heat treatment, during which water is lost and the Maillard reaction develops, leading to the generation of a variety of compounds (Gu et al., 2010). Some of them are responsible for aroma and color, and are very important for gaining consumer acceptance. The classical method of production of cornflakes begins with mixing grits (large pieces of endosperm free of germ and pericarp) with water, sugar, salt and malt extract. Then the grits are cooked in saturated steam, flaked and toasted in a stream of high temperature air $\left(\sim 230^{\circ} \mathrm{C}\right)$ for a few minutes to obtain the final product (Fast, 2000).

In recent years, various organizations such as the International Agency for Research on Cancer (IARC), Food and Drug Administration (FDA) and the Joint FAO/WHO, have identified a num- 
ber of compounds that are generated during heat treatment as potentially toxic. Such compounds may be formed through multiple pathways in which mainly lipids, carbohydrates or ascorbic acid are thermally degraded. Acrylamide, as well as furans, are some of the most studied reaction products, and their presence and quantification triggered a lot of attention, since they are strongly related to serious health problems (Ramirez-Jimenez, Garcia-Villanova, \& Guerra-Hernandez, 2000; Rehman, Saeed, \& Zafar, 2000; Chavez-Servin, Romeu-Nadal, Castellote, \& Lopez-Sabater, 2006; Gokmen \& Senyuva, 2006). However, some other compounds are generated under the same processing conditions, including furfurals (HMF, furfural, 5-methylfurfural), pyrrols and pyridines, whose concentration depends on the severity of the heat treatment. Furthermore, a correlation between acrylamide and hydroxymethylfurfural formation in a wide variety of foods has been found (Delgado-Andrade, Morales, Seiquer, \& Pilar Navarro, 2010). These compounds have been identified in a wide range of foods containing carbohydrates such as processed fruits (RadaMendoza, Sanz, Olano, \& Villamiel, 2004), honey (Fallico, Zappala, Arena, \& Verzera, 2004), milk (Morales \& Jimenez-Perez, 2001), extruded cereals (Rufián-Henares, Delgado-Andrade, \& Morales, 2006) (e.g. breakfast and infant cereals), crackers and bread (Ameur, Mathieu, Lalanne, Trystram, \& Birlouez-Aragon, 2007; Soong, Tan, Leong, \& Henry, 2014), but they can also occur directly by heating hexose. In general, HMF is known as one of the most common intermediate products of overprocessed foods (Akkan, Özdemir, \& Ekiz, 2001; Rada-Mendoza et al., 2004). The toxicological relevance of HMF is not yet fully understood as in vitro studies on genotoxicity and mutagenicity have given controversial results (Abraham et al., 2011).

The most widely accepted methods for the quantification of furfurals in solid foods involve an aqueous extraction, followed by clarification either with Carrez solutions (Chavez-Servin et al., 2006; Delgado-Andrade, Rufian-Henares, \& Morales, 2008; Oral, Dogan, Sarioglu, \& Toker, 2012) or with trichloroacetic acid (Ameur et al., 2007), and sometimes combined with an hydrolysis method (Oral, Mortas, Dogan, Sarioglu, \&
Yazici, 2014) before HPLC-UV analysis. Besides these low molecular weight compounds, during the development of the Maillard reaction, fluorescent compounds and brown pigments are also formed (Matiacevich \& Buera, 2006). The behavior of these easy to measure compounds, as adequate Maillard reaction markers, depends on the reaction conditions and the system's composition. Since the total amount of fluorescent compounds is the sum of those which are free and those bound to proteins (DelgadoAndrade, Rufian-Henares, \& Morales, 2006), the analytical determination has previously been improved with a first stage of protein hydrolysis with pronase (consisting on a mix of proteolitic activities) in order to completely release the crosslinked moieties (Delgado-Andrade et al., 2008; Farroni \& del Pilar Buera, 2012). The pronase treatment had initially been proposed to measure brown pigments in dairy products (Palombo, Gertler, \& Saguy, 1984). On this basis, it could also be expected that the same hydrolytic procedure could improve the extracted amount of furfural family compounds, since potential furfurals include free furfurals, furfurals bound to proteins (like Amadori products) and those formed from precursors (Chavez-Servin et al., 2006). From food safety and nutrition standpoints the availability of adequate extraction and quantification methods for furfurals is necessary to ensure better control and safer processing.

The aim of this work was to analyze the effectiveness of protein hydrolysis with pronase as a pretreatment for the evaluation of furfural intermediates during toasting of cornflakes and the parallel development of brown and fluorescent compounds.

\section{Materials and Methods}

\subsection{Sample Preparation}

Corn grits were provided by a local company, and were steam cooked for 120 minutes with other ingredients; salt, sucrose and malt. Table 1 shows the composition of the formulations employed to steam cook $15 \mathrm{~g}$ of grits. Cooked grits were flaked using a hand roller, equilibrated at relative humidities of 70 and $80 \%$, and toasted in an oven 
Pronase aided extraction of Furfurals $\mid 97$

Table 1: Composition of Systems: mass of each ingredient mixed with $15 \mathrm{~g}$ of grits for steam cooking formulations

\begin{tabular}{|c|c|c|c|c|c|c|}
\hline System & $\rightarrow$ & A & B & $\mathrm{C}$ & D & $\mathrm{E}$ \\
\hline Water (g) & & 9 & 9 & 9 & 9 & 6 \\
\hline Salt (g) & & & & & 0.33 & 0.01 \\
\hline Malt (g) & & & 0.33 & & 0.33 & 0.001 \\
\hline Sucrose $(\mathrm{g})$ & & & & 1.23 & 1.23 & 1.23 \\
\hline
\end{tabular}

Table 2: Sample codes, according to the toasting conditions of cornflakes: $\mathrm{a}_{w}$ and times at $230{ }^{\circ} \mathrm{C}$

\begin{tabular}{rcccccccccc}
\hline & A1 & A2 & B1 & B2 & C1 & C2 & D1 & D2 & E1 & E2 \\
\hline $\mathrm{a}_{w}$ & 0.7 & 0.8 & 0.7 & 0.8 & 0.8 & 0.8 & 0.7 & 0.8 & 0.7 & 0.7 \\
time (min) & 2.5 & 2.5 & 1.5 & 1.5 & 1.5 & 2.5 & 2.5 & 2.5 & 1.5 & 2.5 \\
\hline
\end{tabular}

at $230{ }^{\circ} \mathrm{C}$ under forced air flow (as previously determined for optimal color development without burning the product) (Fast, 2000). Cooking formulations, relative humidity and toasting times (shown in Table 2) were selected to obtain samples, with an adequate range of Maillard reaction degrees, (Acevedo, Schebor, \& Buera, 2008) so as to assess the effect of industrial processing variables on product quality. Ten samples with different degrees of browning were obtained to evaluate the effect of pronase hydrolysis on the determination of furfurals, fluorescent compounds and brown pigments.

\subsection{TCA extraction}

$100 \mathrm{mg}$ of ground sample was suspended in $1 \mathrm{~mL}$ of deionized water in a $2 \mathrm{~mL}$ eppendorf tube. Tubes were sonicated for $5 \mathrm{~min}$ and clarified with $0.25 \mathrm{~mL}$ of trichloroacetic acid (TCA) $(40 \%$ $\mathrm{w} / \mathrm{v}$ ) according to method of Ameur, Trystram, and Birlouez-Aragon (2006). Samples were centrifuged at $11000 \mathrm{rpm}$ for $15 \mathrm{~min}$ at $4{ }^{\circ} \mathrm{C}$. Supernatant was collected in a $10 \mathrm{~mL}$ flask and 2 further extractions were performed. Supernatants were combined and the volume was made up to $10 \mathrm{~mL}$ with deionized water. The extracts were passed through a $0.45 \mu \mathrm{m}$ filter to HPLC vials (Agilent Technologies), prior to injection.

\subsection{Pronase extraction}

Samples were hydrolyzed using pronase E, from Streptomyces griseus (Sigma Aldrich), with an activity of 4 units $/ \mathrm{mg}$ (one unit produced $1 \mu \mathrm{mol}$ $\min ^{-1}$ of tyrosine when hydrolyzing casein at $\mathrm{pH}$ 7.5 and $37^{\circ} \mathrm{C}$ ). $125 \mathrm{mg}$ of ground sample was mixed in a $5 \mathrm{~mL}$ flask with $0.375 \mathrm{mg} \mathrm{mL}^{-1}$ of previously diluted pronase in $\mathrm{pH} 8.3$ Sodium Borate buffer $0.1 \mathrm{M}$. Samples were kept at $40{ }^{\circ} \mathrm{C}$ for $48 \mathrm{~h}$ under constant agitation (Farroni \& del Pilar Buera, 2012). Afterwards, samples were centrifuged in $2 \mathrm{~mL}$ eppendorfs under $11000 \mathrm{rpm}$ for 15 min at $4{ }^{\circ} \mathrm{C}$ and then passed through a 0.2 $\mu \mathrm{m}$ filter (Agilent Technologies) to HPLC vials.

\subsection{Fluorescence and brown pigments}

Total fluorescent compounds extractable in aqueous media were quantified after pronase hydrolysis as described in section 2.3. Fluorescence intensity, with excitation at $340 \mathrm{~nm}$, was measured at $504 \mathrm{~nm}$ where the maximum value of the emission spectrum was observed. This technique is specific for fluorescent Maillard intermediates, as previously used by Matiacevich and Buera (2006) and Delgado-Andrade et al. (2008). A spectrofluorometer Ocean Optics model USB 2000 (Ocean Optics Inc., FL, USA) was used. The samples employed for the determination of fluorescence 
$98 \mid$ Cueto et al.

were first measured at $340 \mathrm{~nm}$ and diluted if necessary so as to keep the absorbance values less than 0.1 and thus avoid the inner filter effect of quenching. The linearity of the fluorescence response and the quantification of fluorescence were made on the basis of quinine emission equivalents, with a calibration curve constructed with concentrations of quinine sulphate in the range between 0.05 and $1.00 \mu \mathrm{g} \mathrm{mL}{ }^{-1}$, as described by Matiacevich and Buera (2006). The Relative Standard Deviation (RSD) for this method was $\mathrm{RSD}_{\text {fluorescence }}=20.5 \%$.

The development of extractable brown pigments was also studied after the hydrolysis with pronase by measuring absorbance units at $420 \mathrm{~nm}$ in a UV-Visible spectrophotometer Jasco model V630 (Jasco Corporation, Japan). RSD Abs $420=13.6 \%$

\subsection{Quantification of Furfurals}

HMF, furfural and 5-MF were quantified by RPHPLC in a modification of the procedure proposed by Ameur et al. (2006), after TCA and pronase hydrolysis. An Alliance HPLC system equipped with a diode array detector Waters 2995 was used (Waters, Milford, USA). Samples were separated in a Waters X-Bridge C18 column $2.1 \mathrm{~mm} \times 100 \mathrm{~mm}$ and $3.5 \mu \mathrm{m}$ particle diameter operating at $25{ }^{\circ} \mathrm{C} .5 \%$ acetonitrile was

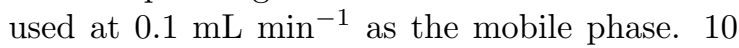
$\mu \mathrm{L}$ of sample was injected and the absorbance was monitored at $284 \mathrm{~nm}$. All samples were analyzed in duplicate and the results expressed in milligrams per kilogram of dry sample (ppm db). Retention times where $7.4 \mathrm{~min}$ for HMF, $10 \mathrm{~min}$ for Furfural, and $15.3 \mathrm{~min}$ for 5MF. All standards were supplied by Sigma Aldrich. Calibration curves were constructed for each analyte using the external standard method. The limit of quantification was calculated to be below 0.05 ppm for all three compounds using the signal to noise ratio. The RSD for the pronase extraction method followed by the HPLC were: HMF $\mathrm{RSD}_{\text {pronase }}=12 \%$, Furfural $\mathrm{RSD}_{\text {pronase }}=15 \%$, and $5 \mathrm{MF} \mathrm{RSD}_{\text {pronase }}=15 \%$. Using the TCA extraction method, the relative standard deviatins for $\mathrm{HMF}$ and Furfural were RSDTCA $=8 \%$ and $\mathrm{RSD}_{T C A}=13 \%$ respectively.. $5 \mathrm{MF}$ was not detected with this extraction procedure.

\subsection{Color Measurement}

Color changes during toasting were determined by image analysis. A computer vision system consisting of a standard gray box (luminance 50 Munsell scale) was employed. The interior of the box had a D65 illumination system located in the upper part which is designed to simulate daylight (Rodríguez-Pulido, Heredia, Zaldívar-Cruz, \& González-Miret, 2012). The images were taken with a digital camera (EOS 40D, Canon, Inc., USA) located at an angle of $45^{\circ}$ with the plane of the sample (Francis \& Clydesdale, 1975) at a distance of $60 \mathrm{~cm}$ from the lens. Image acquisition was performed by a computer program using the remote capture Eos Utility (Canon Inc., USA). Camera settings were: shutter speed $1 / 8$ seconds (no zoom, no flash), macro focus mode, opening $\mathrm{f}=6.3$, and ISO 100 . The images were obtained with a resolution of $3888 \times 2592$ pixels and saved in JPEG format. The obtained photographs were analyzed using Adobe PhotoShopCS4 software and color parameters were expressed in CIELAB space $\left(\mathrm{L}^{*}, \mathrm{a}^{*}\right.$ and $\mathrm{b}^{*}$ ) according to the procedure described by Yam and Papadakis (2004). Photo shop software allowed precise selection of the sample area for color quantification thereby avoiding shadowed zones. Plastic capsules were filled with samples to a height of $1.5 \mathrm{~cm}$ at which point the sample behaves as an opaque system without background effect on the color (Farroni \& del Pilar Buera, 2012). Three photos were taken of each sample, rotating $90^{\circ}$ in between. Color changes were assessed throughout the variables $\mathrm{L}^{*}, \mathrm{a}^{*}$ and $\mathrm{b}^{*}$.

\subsection{Water content}

In order to express the results on a dry matter basis, the water content of the studied samples were determined gravimetrically. Samples were ground in a mill and aliquots of about $500 \mathrm{mg}$ were dried at $130{ }^{\circ} \mathrm{C}$ in $2 \mathrm{~cm}$ diameter aluminum crucibles for $1 \mathrm{~h}$. Triplicates were performed and the average of the results was employed to calculate dry matter. 


\subsection{Statistical analysis}

Differences between methods were evaluated by ANOVA, with Tukey post test, using Infostat 2012 (Grupo InfoStat, FCA, Universidad Nacional de Córdoba, Argentina). Graphs and correlation analysis were performed using GraphPad Prism version 5.00 for Windows (GraphPad Software, San Diego California USA).

\section{Results and Discussion}

\subsection{Furfurals' quantification}

Figure 1 ( $\mathrm{a}$ and $\mathrm{b}$ ) shows the HMF values for the different samples studied. HMF concentrations span a wide range (10 to $3500 \mathrm{ppm}$ ), due to the different formulations and processing conditions, and were thus separated into two groups so as to obtain a better understanding of the results: samples SL, with low furfurals' concentration (lower than 30 ppm, Figure 1a) and samples $\mathrm{SH}$, with high furfurals' concentration (between 100 and 3500 ppm, Figure 1b). Samples of the SH group were visually dark. Although solubilization in water, followed by protein precipitation in trichloroacetic acid, has been considered the best extraction procedure for assessing the amount of HMF accumulated during the baking process (Ameur et al., 2006), the pronase hydrolysis pretreatment yielded greater HMF concentrations than the TCA technique for HMF values over 1000 ppm. HMF concentrationss obtained with pronase hydrolysis were up to $60 \%$ higher than those obtained with the non hydrolytic method. This was the case of samples with treatments D1 and E2.

Although the mean values with pronase extraction for samples over $50 \mathrm{ppm}$ were higher than those obtained with the TCA method, no statistical differences could be established between both extraction methods at concentrations lower than 1000 ppm.

It has been reported that HMF can bind to proteins (Chavez-Servin et al., 2006) such as casein and gluten (Oral et al., 2014) thus making its solubilization and quantification difficult. Sample hydrolysis has the advantage of releasing furfurals originally bound to the proteins and those that could have reacted while the sample was stored for analysis. The increased furfural content difference between both extraction methods at higher concentrations of furfurals could be explained on the basis of the greater proportion of trapped pigments present in the matrix, relative to the total amount, when a higher pigment amount was generated through the Maillard reaction.

In general, samples with added sucrose and malt showed an HMF concentration over 100 ppm, which was higher than the sum of the HMF concentrations corresponding to formulations with either malt or sucrose only. The sample with sucrose but without malt (C) showed the lowest HMF concentration amongst this group. When comparing samples D and E, a higher malt concentration in the formulation favored HMF formation.

Similar to HMF findings, furfural concentrations obtained with the pronase pretreatment were higher than those obtained with the TCA method (Figure 2). Significant differences between both extraction techniques were found for samples formulated with malt, sucrose and salt, and toasted for $2.5 \mathrm{~min}$ (systems D1, D2 and E2). In the case of system E, which had a lower malt content compared to $\mathrm{D}$, the furfural formation was mainly influenced by toasting time. For the lowest furfurals' concentration (around $6 \mathrm{ppm}$ ), pronase extraction yielded a better recovery, up to $300 \%$ higher than for other treatments (samples B1 and C2), although these differences were not statistically significant. It should be noted that 5 methylfurfual (5MF) was not detected in any of the studied samples extracted with TCA but was quantified with the pronase extraction method in all ten samples (Figure 3).

\subsection{HMF concentration by different extraction methods}

The correlation between HMF concentrations, obtained by both extraction methods, is plotted in Figure 4. As previously mentioned due to the wide range (10 to $3500 \mathrm{ppm}$ ) from low HMF concentration samples (SL) to HMF high concentration samples (SH) these two groups of samples were plotted separately. For the lowest 

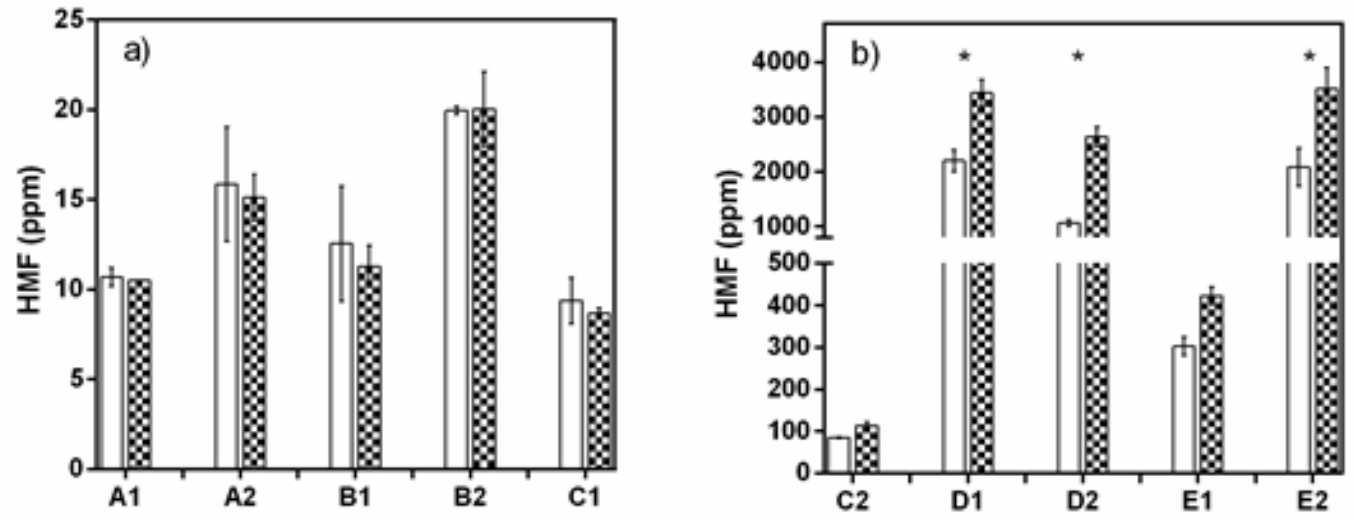

TCA - $\square$

Pronase - $\mathbb{Q}$

Figure 1: HMF values in ppm for the samples extracted using TCA and pronase. a) Samples SL with HMF concentrations lower than 30 ppm. b) Samples SH with values of HMF between $100-4000$ ppm. Asterisk indicates significant differences between TAC and pronase extraction with $\mathrm{P}<0.001$
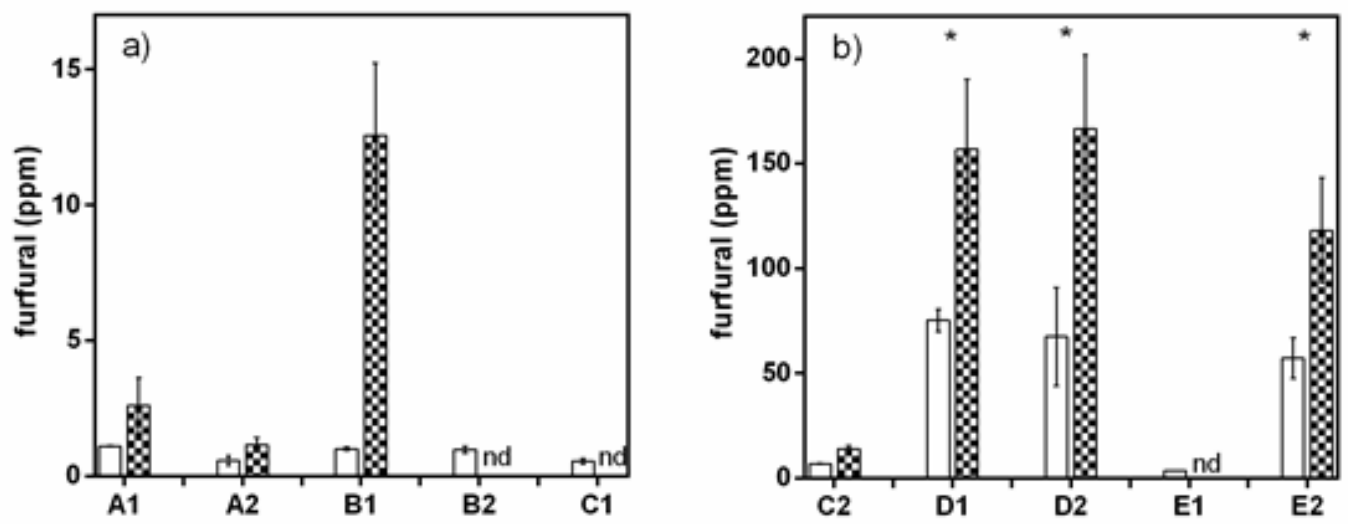

TCA -

Pronase - B

Figure 2: Furfural values in ppm for the samples extracted using TCA and pronase. a) shows the 5 samples with high Furfural values (up to $120 \mathrm{ppm}$ ) (except for E1). b) shows the 5 samples with Furfural concentrations lower than $7 \mathrm{ppm}$. Asterisk indicates significant differences between TAC and pronase extraction con $\mathrm{P}<0.001$. nd: non detectable 
Pronase aided extraction of Furfurals $\mid 101$

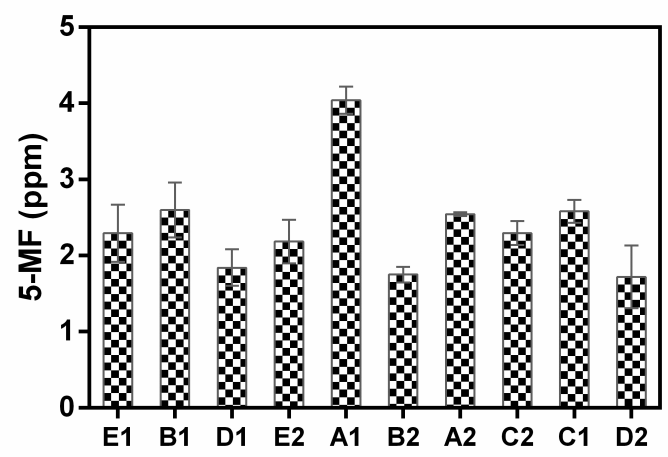

Figure 3: 5-MF concentration in ppm obtained for all 10 samples using the pronase aided extraction. In TCA extracted samples this compound was not detected

HMF, ppm

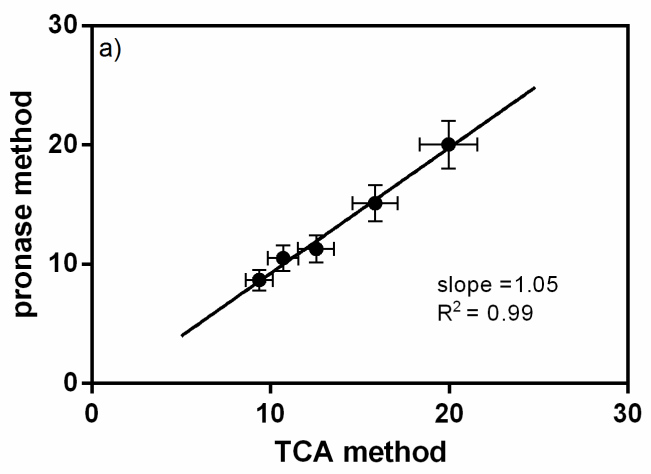

HMF, ppm

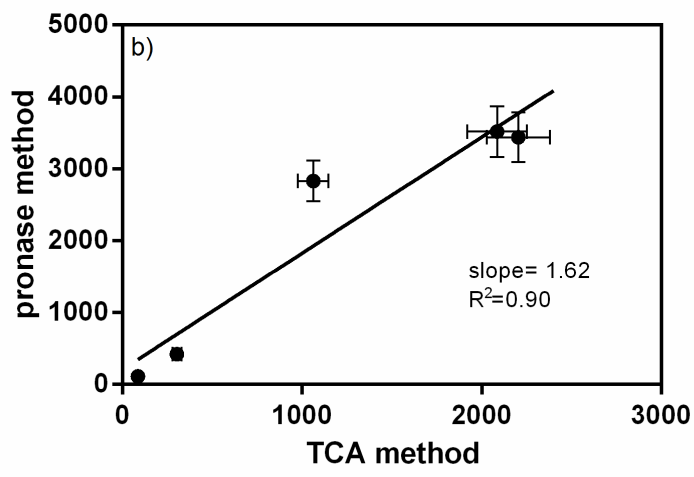

Figure 4: Correlation between TCA and pronase methods for HMF (ppm) concentration values obtained for the 10 samples. Two different linear correlations were plotted. a) SL samples, with the lowest values $\left.\left(\mathrm{m}=1.05, \mathrm{R}^{2}=0.99\right) \mathrm{b}\right) \mathrm{SH}$ samples, with the highest values $\left(\mathrm{m}=1.62, \mathrm{R}^{2}=0.9\right)$. 
HMF values, the slope was about 1 with a $R^{2}$ $=0.99$. For higher values of HMF (higher than $100 \mathrm{ppm}$ ) the slope obtained was 1.6 , with an $\mathrm{R}^{2}$ of 0.90 , indicating a higher degree of change for pronase pretreated samples and showing a higher sensitivity for this enzymatic extraction method in the higher concentration region.

\subsection{Correlation between HMF and luminosity}

The quantity of HMF obtained by both methods was related to the difference between Initial luminosity $\left(\mathrm{L}_{0} *\right)$ and luminosity after toasting $\left(\mathrm{L}^{*}\right)$. A linear correlation was observed when HMF values were higher than 300 ppm (Figure $5)$. When both extraction methods were compared, the highest slope of the correlation between $\mathrm{HMF}$ and $\left(\mathrm{L}_{o}{ }^{*}-\mathrm{L}^{*}\right)$ was obtained when using the pronase extraction method, indicating a more sensitive relationship between luminosity and HMF with this method. It is interesting to note that, at low HMF values, $\left(\mathrm{L}_{o}{ }^{*}-\mathrm{L}^{*}\right)$ of samples varied considerably (about 10 units), indicating the formation of furfurals is delayed compared to color development, and that $\left(\mathrm{L}_{o}{ }^{*}\right.$ $\left.\mathrm{L}^{*}\right)$ is a more sensitive parameter for evaluating the toasting process at early stages. Since $\left(\mathrm{L}_{o}{ }^{*}\right.$ $\left.\mathrm{L}^{*}\right)$ is performed rapidly and non-destructively, this could be an advantage for monitoring the advance of browning reactions at those early stages.

\subsection{Correlation between fluorescence and absorbance with luminosity changes for the pronase-pretreated samples}

As shown in Figure 6, the absorbance values at $420 \mathrm{~nm}$ showed a linear correlation $\left(\mathrm{R}^{2}=0.93\right)$ with the luminosity changes over the whole luminosity range, while the fluorescence development followed a nonlinear behavior, increasing sharply at shorter toasting times $\left(\mathrm{L}_{o}{ }_{-}-\mathrm{L}^{*}\right)$ and then leveling off to reach a plateau value. It can also be observed that the fluorescence development increased faster than the absorbance values at the higher $\mathrm{L}$ values, corresponding to for- mulations with less reactive compounds and/or shorter toasting times.

With an excitation wavelength at $340 \mathrm{~nm}$ and emission at $460 \mathrm{~nm}$, the fluorescence associated with Maillard reaction products is clearly distinguishable from that associated to tryptophan, which has an excitation wavelenght at $290 \mathrm{~nm}$ and emission at $336 \mathrm{~nm}$. The presence of fluorescent intermediates has been correlated to the intensity of the processing conditions applied during the manufacture of breakfast cereals (Delgado-Andrade et al., 2008).

These results indicate that fluorescence development is the most sensitive parameter to follow during the initial stages of the browning reaction, even more so than $\left(\mathrm{L}_{o} * \mathrm{~L}^{*}\right)$ which was found to have a faster response than furfurals' concentration as previously mentioned in section 3.3.

\section{Conclusions}

The relative amounts of the different Maillard reaction products formed during heat treatment are highly dependent on the formulation and process conditions. Thus, for an adequate control of the reaction, it is crucial to specify adequate markers at the different stages of the reaction. Since protein matrices bind intermediate Maillard reaction products such as furfurals and fluorescent compounds, their hydrolysis allows their release and, thus, a more accurate quantification. Regarding the extraction procedures for furfurals, results from both extraction methods for HMF determination showed a high correlation at early and advanced stages of the Maillard reaction. However, whilst at early stages the HMF concentrations evaluated after TCA treatment and pronase hydrolysis were equivalent, at advanced stages the use of pronase in the extraction media allowed a higher recovery of furfurals. Thus, protein hydrolysis can be regarded as a useful pretreatment to better quantify Maillard reaction markers at high toasting times or other drastic treatment conditions. This can help to better understand and control cereal processing technologies and to evaluate which conditions favor the reaction development up to later stages. Regarding the reaction markers, at early reaction times, HMF concentrations increased very 
Pronase aided extraction of Furfurals $\mid 103$
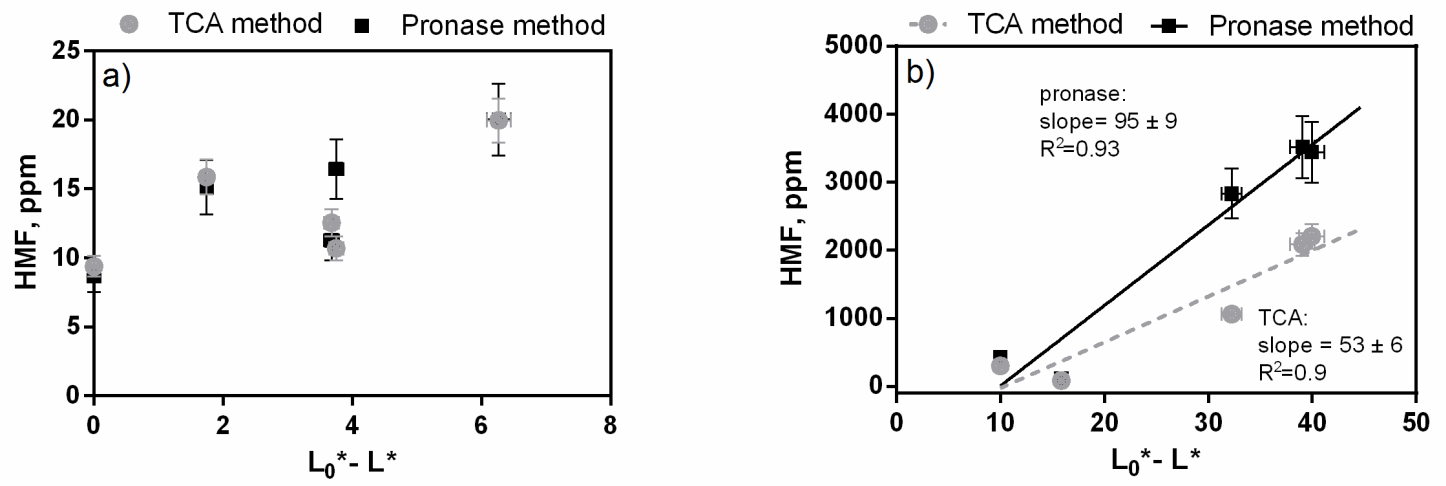

Figure 5: Difference between Initial luminosity and luminosity $\left(\mathrm{L}_{0} *-\mathrm{L}^{*}\right)$ at a given time was plotted with the HMF (ppm) values obtained with both methods (pronase and TCA): a) SL samples; b) SH samples. Linear correlations were obtained with $\mathrm{m}=53.09 \pm 6.23, \mathrm{R}^{2}=0.9$ for $\mathrm{TCA}$ and $\mathrm{m}=94.78 \pm$ $8.62, \mathrm{R}^{2}=0.93$ for the 5 darker samples

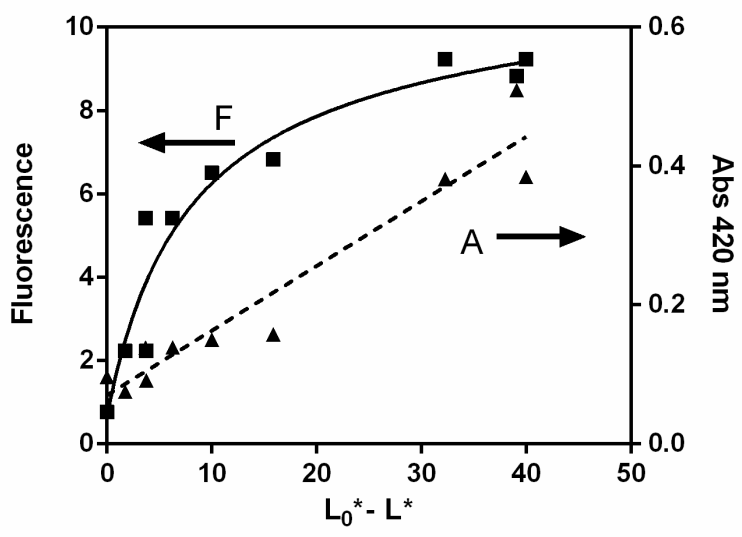

Figure 6: The absorbance values at $420 \mathrm{~nm}(\boldsymbol{\Delta})$ plotted with the luminosity changes showed a linear correlation $\left(\mathrm{m}=9.3 * 10^{-3}, \mathrm{R}^{2}=0.93\right)$ over the whole luminosity range. Fluorescence values expressed as quinine $(\mathrm{ppm})(\boldsymbol{\square})$ followed a nonlinear behavior 
slightly while $\left(\mathrm{L}_{0} * \mathrm{~L}^{*}\right)$ showed a considerable increase. The most sensitive parameter for monitoring the early reaction steps in the toasting process was the measure of fluorescent compounds, after protein hydrolysis with pronase, up to $\left(\mathrm{L}_{0} * \mathrm{~L}^{*}\right)$ values of 10 units. Sample darkening, as determined by the colorimetric analysis $\left(\mathrm{L}_{0} * \mathrm{~L}^{*}\right)$ was also adequate at these early stages, although not as sensitive as fluorescence. The absorbance measurement after the enzymatic treatment with pronase did not show any advantages, in comparison with the proposed fluorescence and furfurals' quantification variables.

Although the hydrolysis step is time-consuming and may be regarded as a drawback, afterwards the determinations are easy and fast and it serves as a pretreatment for the quantification of intermediates and final products of the Maillard reaction (furfurals, fluorescence and brown compounds, for example).

The proposed enzymatic pretreatment (either at early or advanced stages) is economically feasible, easy to perform, does not use any potentially harmful solvent, and improves the accuracy during quantification of furfurals in toasted cereal samples.

\section{Acknowledgements}

The authors would like to thank UBACYT X024, CONICET (PIP 100846), ANPCYT (PICT 1331) and INTA PNAyAV 1130043 for their financial support.

\section{References}

Abraham, K., Guertler, R., Berg, K., Heinemeyer, G., Lampen, A., \& Appel, K. E. (2011). Toxicology and risk assessment of 5-hydroxymethylfurfural in food. Molecular Nutrition 85 Food Research, 55(5), 667678. doi:10.1002/mnfr.201000564

Acevedo, N. C., Schebor, C., \& Buera, P. (2008). Non-enzymatic browning kinetics analysed through water-solids interactions and water mobility in dehydrated potato. Food Chemistry, 108(3), 900-906. doi:10.1016/j. foodchem.2007.11.057
Akkan, A. A., Özdemir, Y., \& Ekiz, H. L. (2001). Derivative spectrophotometric determination of 5-(hydroxymethyl)-2-furaldehyde (hmf) and furfural in locust bean extract. Food/Nahrung, 45(1), 43-46.

Ameur, L. A., Trystram, G., \& BirlouezAragon, I. (2006). Accumulation of 5hydroxymethyl-2-furfural in cookies during the backing process: validation of an extraction method. Food Chemistry, 98(4), 790-796. doi:10.1016/j.foodchem.2005.07. 038

Ameur, L. A., Mathieu, O., Lalanne, V., Trystram, G., \& Birlouez-Aragon, I. (2007). Comparison of the effects of sucrose and hexose on furfural formation and browning in cookies baked at different temperatures. Food Chemistry, 101 (4), 1407-1416. doi:10.1016/j.foodchem.2006.03.049

Chavez-Servin, J. L., Romeu-Nadal, M., Castellote, A. I., \& Lopez-Sabater, M. C. (2006). Evolution of free mono- and di-saccharide content of milk-based formula powder during storage. Food Chemistry, 97(1), 103108. doi:10.1016/j.foodchem.2005.03.027

Delgado-Andrade, C., Morales, F. J., Seiquer, I., \& Pilar Navarro, M. (2010). Maillard reaction products profile and intake from spanish typical dishes. Food Research International, 43(5), 1304-1311. doi:10.1016/j. foodres.2010.03.018

Delgado-Andrade, C., Rufian-Henares, J. A., \& Morales, F. J. (2006). Study on fluorescence of maillard reaction compounds in breakfast cereals. Molecular Nutrition $\&$ Food Research, 50(9), 799-804. doi:10 . $1002 /$ mnfr. 200500249

Delgado-Andrade, C., Rufian-Henares, J. A., \& Morales, F. J. (2008). Optimised procedure to analyse maillard reaction-associated fluorescence in cereal-based products. Czech Journal of Food Sciences, 26(5), 339-346.

Fallico, B., Zappala, M., Arena, E., \& Verzera, A. (2004). Effects of conditioning on hmf content in unifloral honeys. Food Chemistry, 85(2), 305-313. doi:10.1016/j.foodchem. 2003.07.010

Farroni, A. \& del Pilar Buera, M. (2012). Colour and surface fluorescence development and their relationship with mail lard reaction 
markers as influenced by structural changes during cornflakes production. Food Chemistry, 135(3), 1685-1691. doi:10.1016/j . foodchem.2012.05.114

Fast, R. B. (2000). Manufacturing technology of ready-to-eat breakfast cereals. In Breakfast cereals and how they are made, 2nd ed. (R. B. Fast \& E. F. Caldwell, Vol. 1, pp. 17-54). St. Paul, Minesota, USA: American Association of Cereal Chemist.

Francis, F. J. \& Clydesdale, F. M. (1975). Food colorimetry: theory and applications. AVI Publishing Co. Inc.

Gokmen, V. \& Senyuva, H. Z. (2006). Improved method for the determination of hydroxymethylfurfural in baby foods using liquid chromatography-mass spectrometry. Journal of Agricultural and Food Chemistry, 54 (8), 2845-2849. doi:10.1021/jf053091y

Gu, F.-L., Kim, J. M., Abbas, S., Zhang, X.-M., Xia, S.-Q., \& Chen, Z.-X. (2010). Structure and antioxidant activity of high molecular weight maillard reaction products from casein-glucose. Food Chemistry, 120(2), 505-511. doi:10.1016/j.foodchem.2009.10. 044

Matiacevich, S. B. \& Buera, M. P. (2006). A critical evaluation of fluorescence as a potential marker for the maillard reaction. Food Chemistry, 95(3), 423-430. doi:10.1016/j. foodchem.2005.01.027

Morales, F. J. \& Jimenez-Perez, S. (2001). Hydroxymethylfurfural determination in infant milk-based formulas by micellar electrokinetic capillary chromatography. Food Chemistry, 72(4), 525-531. doi:10.1016/ S0308-8146(00)00284-3

Oral, R. A., Dogan, M., Sarioglu, K., \& Toker, O. S. (2012). 5-hydroxymethyl furfural formation and reaction kinetics of different pekmez samples: effect of temperature and storage. International Journal of Food Engineering, 8(4).

Oral, R. A., Mortas, M., Dogan, M., Sarioglu, K., \& Yazici, F. (2014). New approaches to determination of hmf. Food Chemistry, 143, 367-370. doi:10.1016/j.foodchem.2013.07. 135

Palombo, R., Gertler, A., \& Saguy, I. (1984). A simplified method for determination of browning in dairy powders. Journal of Food Science, 49(6), 1609-\&. doi:10.1111/ j . 1365-2621.1984.tb12855.x

Rada-Mendoza, M., Sanz, M., Olano, A., \& Villamiel, M. (2004). Formation of hydroxymethylfurfural and furosine during the storage of jams and fruit-based infant foods. Food Chemistry, 85(4), 605609. doi:10.1016/j.foodchem.2003.07.002

Ramirez-Jimenez, A., Garcia-Villanova, B., \& Guerra-Hernandez, E. (2000). Hydroxymethylfurfural and methylfurfural content of selected bakery products. Food Research International, 33(10), 833-838. doi:10.1016/S0963-9969(00)00102-2

Rehman, Z. U., Saeed, A., \& Zafar, S. I. (2000). Hydroxymethylfurfural as an indicator for the detection of dried powder in liquid milk. Milchwissenschaft-milk Science International, 55(5), 256-257.

Rodríguez-Pulido, F., Heredia, F., ZaldívarCruz, J., \& González-Miret, M. 1. (2012). Application of image analysis to the colorphenolic composition relationships of grape seeds. In Color in food (pp. 113-120). Boca Raton: CRC Press. doi:10.1201/b11878-15

Rufián-Henares, J. A., Delgado-Andrade, C., \& Morales, F. J. (2006). Analysis of heatdamage indices in breakfast cereals: influence of composition. Journal of Cereal Science, 43(1), 63-69. doi:10.1016/j.jcs.2005. 05.001

Soong, Y. Y., Tan, S. P., Leong, L. P., \& Henry, J. K. (2014). Total antioxidant capacity and starch digestibility of muffins baked with rice, wheat, oat, corn and barley flour. Food Chemistry, 164, 462-469. doi:10.1016/j.foodchem.2014.05.041

Tessier, F. J. \& Birlouez-Aragon, I. (2012). Health effects of dietary maillard reaction products: the results of icare and other studies. Amino Acids, 42(4), 1119-1131. doi:10.1007/s00726-010-0776-z

Yam, K. L. \& Papadakis, S. E. (2004). A simple digital imaging method for measuring and analyzing color of food surfaces. Journal of Food Engineering, 61(1), 137-142. doi:10. 1016/S0260-8774(03)00195-X 